\title{
Which distance-decay function for migration and which one for commuting? A case study of Slovenia
}

\author{
Samo Drobne ${ }^{1, *}$ and Mitja Lakner ${ }^{1}$ \\ ${ }^{1}$ Faculty of Civil and Geodetic Engineering, University of Ljubljana \\ Jamova cesta 2, 1001 Ljubljana, Slovenia \\ E-mail: 〈\{samo.drobne, mitja.lakner\}@fgg.uni-lj.si〉
}

\begin{abstract}
The volume of social interactions like migration and commuting between two locations depends significantly on the distance between them. In the paper, we analysed the shape and parameters of several distance-decay functions for commuting and for migration flows, respectively. The analysis was performed for inter-municipal interactions in Slovenia in 2010-2011. The functions considered were power, exponential, normal, square root exponential, hyperbolic, power-exponential, and normalized powerexponential distance-decay functions. Distance was considered in three ways: as the Euclidean distance, as the shortest road distance, and as the fastest road distance between municipal centres under consideration. The analysis was performed for the whole set of interactions in the state, as well as for interactions to specific urban centres. We demonstrate that the power-exponential distance-decay function fits best for all analysed cases. The determination coefficients for this type of function are low when analysing all data together, but they increase significantly when distance-decay functions are modelled for urban centres at different levels of consideration.
\end{abstract}

Key words: distance-decay function, spatial interaction, intensity of interaction, commuting, migration, Slovenia

Received: September 19, 2014; accepted: December 7, 2014; available online: December 30, 2014

\section{Introduction}

One of the most important concepts in spatial sciences (e.g., urban and regional geography, economic geography, spatial planning) is the concept of distancedecay. Many researchers of spatial interaction systems (e.g., Ravenstein [19], Stewart [23, 24], Olson [18], Tobler [28], Taylor [25, 26], Fotheringham [8, 9, 10], Haynes and Fotheringham [14], Fotheringham and O'Kelly [11]) proved that the intensity of interactions in space depends significantly on the distance between pairs of the considered locations. Fotheringham defined the distance-decay concept as follows [9: 425]: "A distance-decay parameter measures the

${ }^{*}$ Corresponding author. 
relationship between observed interaction patterns and distance when all other determinants of interaction are constant. This relationship is assumed to be an accurate reflection of the perception of distance as a deterrent to interaction." All other determinants of interaction, along with distance, can be measured in spatial interaction models (SIM).

Cesario [2, 3] showed that a general spatial interaction model can be formulated as:

$$
I_{i j}=q\left(d_{i j}, E_{i}, A_{j}\right),
$$

where $I_{i j}$ is the interaction between origin $i$ and destination $j, d_{i j}$ is the distance between origin $i$ and destination $j, E_{i}$ is the emissiveness in the origin $i, A_{j}$ is the attractiveness in the destination $j$, and $q$ is the function of all three variables. Fotheringham $[8,9,10]$ showed that the distance function, $f\left(d_{i j}\right)$, is an independent function in spatial interaction models. It follows that model (1) can be written as the product of distance function, $f\left(d_{i j}\right)$, function of emissiveness, $g\left(E_{i}\right)$, and function of attractiveness, $h\left(A_{j}\right)$ :

$$
I_{i j}=f\left(d_{i j}\right) \cdot g\left(E_{i}\right) \cdot h\left(A_{j}\right) .
$$

Consequently, in different variants of spatial interaction models and their applications, a distance function (also a distance-decay function) can be considered independently.

Taylor $[25,26]$ showed that the intensity of interaction in a distance function must be considered relative to the origin. Spatial interactions can be normalized according to the population in the origin or according to the area of origin.

Many scientists have investigated the interrelation between migration and commuting, e.g., Yapa et al. [30], Evers and Van der Veen [7] and, most recently, Lundholm [15]. Commuting can be considered as a substitute to migration if work and residence are geographically separated, but they can also be considered as a complement if a person chooses to move away from their workplace locality, and then commutes to work [7]. The latter is one of the main causes of suburbanisation. If there are conditions that allow (daily) commuting, people often choose to commute instead of moving closer to their work. And vice versa: poor commuting conditions can be perceived as a prerequisite for moving [6].

De Vries et al. [4] provided evidence that the choice of the functional form for the distance function makes an important difference for predictions (e.g., concerning the effects of infrastructure improvements on commuting flows). Consequently, the aim of this paper is to analyse various distance-decay functions for migration and commuting in Slovenia. Furthermore, in this paper we demonstrate that distance-decay models fit better to empirical data when 
they are modelled for specific urban centres than for the whole set of interactions in the state.

\section{Methodology}

We considered migration interactions, $M_{i j}$, and commuting interactions, $C_{i j}$, between all municipalities in Slovenia in 2010-2011. There were 210 municipalities in Slovenia at the time, so $43,890(210 \cdot 209)$ interactions were analysed. Data on both migration and commuting were obtained from the Statistical Office of the Republic of Slovenia [22], separately for each year. To make the results more trustworthy (to avoid the effect of various impacts over one year only), data for two different years were combined in a single database and average values were calculated. The data we used were on the low level of aggregation, so the dataset was large. But, out of 43,890 inter-municipal interactions, $67.4 \%$ of migration flows and $68.6 \%$ of commuting flows were 0 (empty). The highest migration flow was 540.5 migrants from the capital city of Ljubljana to the nearby town of Domžale (the Euclidean distance is $13 \mathrm{~km}$ only), and the highest commuting flow of 6,597.5 was in the opposite direction, i.e., from Domžale to Ljubljana.

In the analysis, the distance was considered in three ways: as the Euclidean distance, as the shortest road distance, and as the fastest road distance between municipal centres under consideration. Road networks for 2010 and 2011 were modelled in software ArcGIS using the data on state roads [21]. Distances were calculated as origin-destination (OD) matrices in ArcGIS, separately for 2010 and 2011 and combined as an average distance.

The parameters of distance-decay functions were analysed for the whole sets of migration and commuting of inter-municipal interactions in Slovenia, and for the subsets of interaction terminating in different types of urban centres of Slovenia. The concept of Slovenia's urban system was defined in the Spatial Development Strategy of Slovenia [27]. In SDSS, a total of 50 urban centres with 61 towns and other urban settlements are defined, including conurbations, at all levels of investigation. Figure 1 shows the concept of settlements by defining the hierarchy of urban centres of Slovenia. Officially, the urban centres at the higher level are also included in the group of the centres at the lower level. However, for the purpose of this paper where we analysed the differences of distance functions to different types of urban centres, the centres at the higher level(s) were excluded from the urban centres at the lower level(s). According to [27], there are three national urban centres of international significance (Ljubljana, Maribor and coastal conurbation Koper-Izola-Piran; centres 1), 12 urban centres of national significance (8 towns, Murska Sobota, 
Ptuj, Celje, Velenje, Kranj, Novo mesto, Postojna, Nova Gorica, and 4 conurbations, Jesenice-Radovljica, Zagorje ob Savi-Trbovlje-Hrastnik, Slovenj Gradec-Ravne na Koroškem-Dravograd, Brežice-Krško-Sevnica; centres 2-1), 15 urban centres of regional significance (13 towns and 2 conurbations, Domžale-Kamnik, Šmarje pri Jelšah-Rogaška Slatina, centres 3-2-1), and 20 urban centres of inter-municipal significance (centres 4-3-2-1).

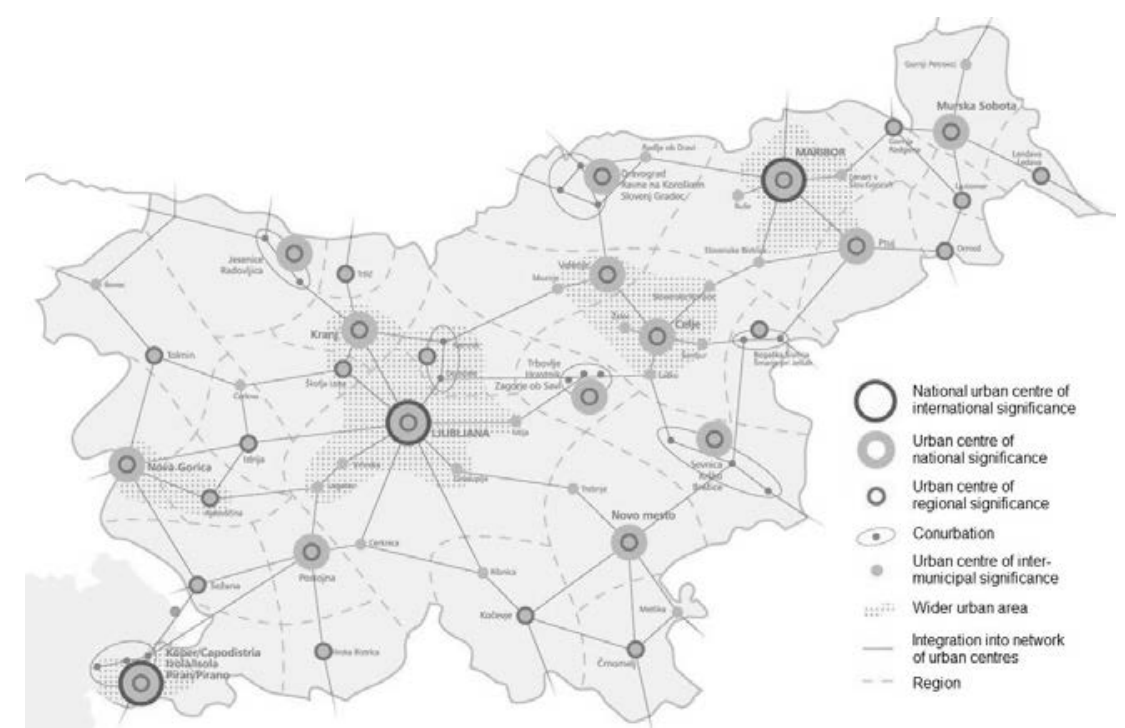

Figure 1: Hierarchy of urban centres with wider urban and functional urban areas in the concept of the polycentric urban system of Slovenia [27: 24]

According to de Vries et al. [4], commuting behaviour within a municipality apparently differs from that between municipalities. Therefore, we omit the observations on intra-zonal - in our case intra-municipal - flows from the analysis.

The distance-decay functions were constructed in $x y$ graphs, where the $x$ axis showed the distance (in kilometres) from the municipality of origin to the destinations, while the $y$ axis gave the proportion of interactions (migration or commuting flows) from the specific municipality to the considered destination out of the total number of out-flows from the origin.

In the case of the whole set of inter-municipal migrations in the state we considered data

$$
M^{\%}=\left\{\left(d_{i j}, M_{i j}^{\%}\right) ; i \neq j=1,2, \ldots, n\right\},
$$

where $d_{i j}$ is the distance between the municipality of origin $i$ and the municipality of destination $j, n$ is the number of municipalities (in our case, 
$n=210), M_{i j}^{\%}$ is the relative migration from the municipality $i$ to $j$, calculated as the quotient between migration from $i$ to $j, M_{i j}$, and the sum of all migrants from $i$ to all other destinations $j^{\prime}\left(j^{\prime}=1,2, \ldots, n\right), \sum_{j^{\prime}=1, i \neq j^{\prime}}^{n} M_{i j^{\prime}}$ :

$$
M_{i j}^{\%}=\frac{M_{i j}}{\sum_{j^{\prime}=1, i \neq j^{\prime}}^{n} M_{i j^{\prime}}} .
$$

In the case of the whole set of inter-municipal commuters, we considered data

$$
C^{\%}=\left\{\left(d_{i j}, C_{i j}^{\%}\right) ; i \neq j=1,2, \ldots, n\right\},
$$

where $C_{i j}^{\%}$ is relative commuting from $i$ to $j$ calculated as the quotient between commuting from $i$ to $j, C_{i j}$, and the sum of all commuters from $i$ to all other destinations $j^{\prime}\left(j^{\prime}=1,2, \ldots, n\right), \sum_{j^{\prime}=1, i \neq j^{\prime}}^{n} C_{i j^{\prime}}$

$$
C_{i j}^{\%}=\frac{C_{i j}}{\sum_{j^{\prime}=1, i \neq j^{\prime}}^{n} C_{i j^{\prime}}} .
$$

When we analysed migrations and commuting to the specific type of urban centres $k, k=1, \ldots, 5 \quad(k=1$ for national urban centres of international significance (centres 1), $k=2$ for urban centres of national significance (centres $2-1), k=3$ for urban centres of regional significance (centres $3-2-1), k=4$ for urban centres of inter-municipal significance (centres 4-3-2-1), and $k=5$ for all other municipalities), we partitioned the interaction data into five adequate disjoint sets. For each of these sets, we defined $M_{C k, i}^{\%}$ and $C_{C k, i}^{\%}(i=1,2, \ldots, n$, $k=1, \ldots, 5)$, as in (4) and (6). All summations over these subsets in formulas (14), $(17-18)$ are denoted by $\operatorname{dot}(\bullet)$.

For each of these 12 datasets (6 datasets for migrations and 6 datasets for commuting, respectively), we calculated seven different distance-decay functions that expressed the influence of the distance on the intensity of interactions. The tested set of functions consisted of classical functions already suggested by Steward [23], Goux [12], Taylor [25, 26], Johnston [17], Sheppard [20], Wilson [29], and others; see functions (7-10) below. Additionally to this set of functions, we also tested hyperbolic, power-exponential, and normalized powerexponential distance-decay functions; see (11-13) below. Notably, Halas et al. [13] have recently suggested the use of the last two functions (12-13), which fitted most to inter-municipal commuting flows to regional centres in the Czech Republic. So, we fitted seven functions of different forms to the analysed data: 


$$
\begin{array}{ll}
\text { power function } & f(d)=a d^{b}, a>0, b<0 \\
\text { exponential function } & f(d)=a e^{-b d}, a>0, b>0 \\
\text { normal function } & f(d)=a e^{-b d^{2}}, a>0, b>0 \\
\text { square root exponential } & f(d)=a e^{-b \sqrt{d}}, a>0, b>0 \\
\text { hyperbolic function } & f(d)=a+b / d, a \geq 0, b>0 \\
\text { power-exponential } & f(d)=c e^{-a d^{b}}, a>0, b \in \mathbb{R}, c>0 \\
\text { normalized power-exponential } & f(d)=e^{-a d^{b}}, a>0, b \in \mathbb{R}
\end{array}
$$

Distance-decay functions, $f(d)$, were estimated for the whole set of interactions as well as for subsets of interactions to the specific type of urban centres, $k(k=1,2,3,4,5)-$ which is denoted by dot (•) in (14-15) and (17-18). The procedure of estimating parameters $a, b$ and $c$ was performed in software for technical computing Mathematica 10.0 using the least-square method

$$
\sum \cdot\left(\mathfrak{M} \%-f\left(d_{\bullet}\right)\right)^{2}=\min \quad \text { and } \quad \sum \cdot\left(\mathfrak{C}_{\bullet}^{\%}-f\left(d_{\bullet}\right)\right)^{2}=\min ,
$$

where

$$
\mathfrak{M}_{\bullet}^{\%}=M_{i j}^{\%} \text { or } M_{C k, i}^{\%} \quad \text { and } \quad \mathfrak{C}_{\bullet}^{\%}=C_{i j}^{\%} \text { or } C_{C k, i}^{\%}
$$

For each function and for each dataset, standard errors of estimation, $S E E_{\mathfrak{M}}$ or $S E E_{\mathfrak{C}}$, were calculated as the square root of average of (14). Coefficients of determination, $R_{\mathfrak{M}}^{2}$ or $R_{\mathfrak{C}}^{2}$, were calculated as well

$$
R_{\mathfrak{M}}^{2}=1-\frac{S S_{\mathfrak{M}, \text { res }}}{S S_{\mathfrak{M}, \text { tot }}} \text { and } \quad R_{\mathfrak{C}}^{2}=1-\frac{S S_{\mathfrak{C}, \text { res }}}{S S_{\mathfrak{E}, \text { tot }}},
$$

where

$$
S S_{\mathfrak{M}, \text { res }}=\sum \cdot\left(\mathfrak{M} \%_{\bullet}^{\%}-f\left(d_{\bullet}\right)\right)^{2} \text { and } S S_{\mathfrak{C}, \text { res }}=\sum \bullet\left(\mathfrak{C}_{\bullet}^{\%}-f\left(d_{\bullet}\right)\right)^{2}
$$

and

$$
S S_{\mathfrak{M}, t o t}=\sum \cdot\left(\mathfrak{M} \%-\overline{\mathfrak{M}}^{\%}\right)^{2} \text { and } S S_{\mathfrak{C}, t o t}=\sum \cdot\left(\mathfrak{C}_{\bullet}^{\%}-\overline{\mathfrak{C}}^{\%}\right)^{2}
$$

where $\overline{\mathfrak{M}}^{\%}$ is the average value of the relative interaction of migration, and $\overline{\mathfrak{c}} \%$ is the average value of the relative interaction of commuting. 


\section{Results}

Table 1 shows the coefficients of determination for the analysed distance-decay functions for migration according to the Euclidean distance, according to the shortest road distance, and according to the fastest road distance; Table 2 shows the results for commuting.

When comparing the corresponding coefficients of determination by different types of distance, it is evident that, in general, the use of the shortest road distance in the models $(7-13)$ gives the best results $\left(R_{\mathfrak{M}}^{2}\right.$ and $R_{\mathscr{C}}^{2}$ are in corresponding maximums). Here we should note that Drobne and Lakner [5] proved that there were only two regional centres (Slovenj Gradec-DravogradRavne na Koroškem and Trbovlje-Hrastnik-Zagorje ob Savi) in 2011 where better results were obtained using the fastest road distance. However, these two urban conurbations are the only regional centres that are not directly connected to the highway.

\begin{tabular}{|c|c|c|c|c|c|c|c|}
\hline & $\begin{array}{c}\text { Power } \\
\text { function } \\
\quad(7)\end{array}$ & $\begin{array}{l}\text { Exponential } \\
\text { function (8) }\end{array}$ & $\begin{array}{c}\text { Normal } \\
\text { function } \\
\text { (9) }\end{array}$ & $\begin{array}{c}\text { Square root } \\
\text { exponential } \\
\text { function } \\
(10)\end{array}$ & $\begin{array}{c}\text { Hyperbolic } \\
\text { function } \\
(11)\end{array}$ & $\begin{array}{c}\text { Power- } \\
\text { exponential } \\
\text { function } \\
(12)\end{array}$ & \begin{tabular}{|c|} 
Normalized \\
power- \\
exponential \\
function \\
$(13)$
\end{tabular} \\
\hline \multicolumn{8}{|c|}{ Euclidean distance } \\
\hline All interactions & 0.138 & 0.154 & 0.148 & 0.155 & 0.142 & 0.155 & 0.149 \\
\hline To centres at level 1 & 0.398 & 0.456 & 0.437 & 0.450 & 0.353 & 0.457 & 0.429 \\
\hline To centres 2-1 & 0.515 & 0.583 & 0.564 & 0.575 & 0.535 & 0.583 & 0.561 \\
\hline To centres $3-2-1$ & 0.318 & 0.367 & 0.353 & 0.360 & 0.325 & 0.367 & 0.350 \\
\hline To centres 4-3-2-1 & 0.418 & 0.539 & 0.530 & 0.514 & 0.451 & 0.540 & 0.482 \\
\hline To other & 0.328 & 0.396 & 0.390 & 0.384 & 0.345 & 0.396 & 0.363 \\
\hline \multicolumn{8}{|c|}{ Shortest road distance } \\
\hline All interactions & 0.154 & 0.184 & 0.176 & 0.183 & 0.160 & 0.184 & 0.173 \\
\hline To centres at level 1 & 0.397 & 0.484 & 0.470 & 0.468 & 0.332 & 0.484 & 0.436 \\
\hline To centres 2-1 & 0.618 & 0.660 & 0.632 & 0.662 & 0.632 & 0.664 & 0.655 \\
\hline To centres 3-2-1 & 0.334 & 0.379 & 0.364 & 0.376 & 0.346 & 0.380 & 0.367 \\
\hline To centres $4-3-2-1$ & 0.477 & 0.603 & 0.587 & 0.586 & 0.514 & 0.603 & 0.553 \\
\hline To other & 0.326 & 0.425 & 0.418 & 0.409 & 0.351 & 0.426 & 0.375 \\
\hline \multicolumn{8}{|c|}{ Fastest road distance } \\
\hline All interactions & 0.147 & 0.184 & 0.176 & 0.181 & 0.160 & 0.184 & 0.170 \\
\hline To centres at level 1 & 0.352 & 0.418 & 0.398 & 0.410 & 0.320 & 0.418 & 0.389 \\
\hline To centres 2-1 & 0.573 & 0.640 & 0.610 & 0.638 & 0.601 & 0.643 & 0.628 \\
\hline To centres $3-2-1$ & 0.321 & 0.375 & 0.362 & 0.369 & 0.335 & 0.375 & 0.359 \\
\hline To centres 4-3-2-1 & 0.436 & 0.556 & 0.544 & 0.537 & 0.477 & 0.557 & 0.511 \\
\hline To other & 0.296 & 0.405 & 0.400 & 0.384 & 0.332 & 0.406 & 0.348 \\
\hline
\end{tabular}

Table 1: Coefficients of determination for distance-decay functions for intermunicipal migrations in Slovenia in 2010-2011, $R_{\mathfrak{M}}^{2}$ (Note: the bold number denotes the row maximum, the italic one denotes the column maximum, and the shaded cell denotes the maximum for the whole dataset). 
The comparison of coefficients $R_{\mathfrak{M}}^{2}$ and $R_{\mathbb{C}}^{2}$ by functions (7-13) showed that the power-exponential distance-decay function (12) fits best for all analysed cases. However, if a less complex model is desired or requested for a specific analysis (see an example in Halas et al. [13]), model (13) can be used instead of (12) without significant consequences: $R_{\mathfrak{M}}^{2}$ and $R_{\mathfrak{C}}^{2}$ for (13) are just a bit lower than those for (12).

\begin{tabular}{|l|c|c|c|c|c|c|c|}
\hline & $\begin{array}{c}\text { Power } \\
\text { function } \\
(7)\end{array}$ & $\begin{array}{c}\text { Exponential } \\
\text { function }(8)\end{array}$ & $\begin{array}{c}\text { Normal } \\
\text { function } \\
(9)\end{array}$ & $\begin{array}{c}\text { Square root } \\
\text { exponential } \\
\text { function } \\
(10)\end{array}$ & $\begin{array}{c}\text { Hyperbolic } \\
\text { function } \\
(11)\end{array}$ & $\begin{array}{c}\text { Power- } \\
\text { exponential } \\
\text { function } \\
(12)\end{array}$ & $\begin{array}{c}\text { Normalized } \\
\text { power- } \\
\text { exponential } \\
\text { function } \\
(13)\end{array}$ \\
\hline \multicolumn{7}{|c|}{ Euclidean distance } \\
\hline All interactions & 0.112 & 0.140 & 0.139 & 0.134 & 0.121 & $\mathbf{0 . 1 4 1}$ & 0.132 \\
\hline To centres at level & 0.549 & 0.679 & 0.669 & 0.653 & 0.555 & $\mathbf{0 . 6 8 0}$ & 0.678 \\
\hline To centres 2-1 & 0.432 & 0.557 & 0.566 & 0.523 & 0.475 & $\mathbf{0 . 5 6 7}$ & 0.548 \\
\hline To centres 3-2-1 & 0.329 & 0.435 & 0.442 & 0.406 & 0.347 & $\mathbf{0 . 4 4 3}$ & 0.419 \\
\hline To centres 4-3-2-1 & 0.370 & 0.551 & 0.574 & 0.497 & 0.416 & $\mathbf{0 . 5 7 4}$ & 0.508 \\
\hline To other & 0.252 & 0.271 & 0.256 & 0.274 & 0.252 & $\mathbf{0 . 2 7 4}$ & 0.272 \\
\hline \multicolumn{7}{|c|}{ Shortest road distance } \\
\hline All interactions & 0.131 & 0.175 & 0.174 & 0.167 & 0.143 & $\mathbf{0 . 1 7 6}$ & 0.163 \\
\hline To centres at level & 0.561 & 0.730 & 0.725 & 0.694 & 0.550 & $\mathbf{0 . 7 3 3}$ & 0.728 \\
\hline To centres 2-1 & 0.526 & 0.634 & 0.637 & 0.608 & 0.565 & $\mathbf{0 . 6 4 0}$ & 0.629 \\
\hline To centres 3-2-1 & 0.364 & 0.466 & 0.468 & 0.443 & 0.385 & $\mathbf{0 . 4 7 1}$ & 0.454 \\
\hline To centres 4-3-2-1 & 0.419 & 0.613 & 0.627 & 0.566 & 0.471 & $\mathbf{0 . 6 2 7}$ & 0.576 \\
\hline To other & 0.265 & 0.307 & 0.290 & 0.307 & 0.280 & $\mathbf{0 . 3 0 9}$ & 0.302 \\
\hline \multicolumn{7}{|c|}{ Fastest road distance } \\
\hline All interactions & 0.122 & 0.169 & 0.169 & 0.159 & 0.139 & $\mathbf{0 . 1 7 0}$ & 0.157 \\
\hline To centres at level & 0.465 & 0.649 & 0.651 & 0.603 & 0.485 & $\mathbf{0 . 6 5 6}$ & 0.651 \\
\hline To centres 2-1 & 0.467 & 0.592 & 0.592 & 0.562 & 0.522 & $\mathbf{0 . 5 9 6}$ & 0.589 \\
\hline To centres 3-2-1 & 0.348 & 0.456 & 0.459 & 0.429 & 0.370 & $\mathbf{0 . 4 6 2}$ & 0.446 \\
\hline To centres 4-3-2-1 & 0.346 & 0.511 & 0.525 & 0.468 & 0.397 & $\mathbf{0 . 5 2 5}$ & 0.481 \\
\hline To other & 0.247 & 0.300 & 0.285 & 0.295 & 0.265 & $\mathbf{0 . 3 0 0}$ & 0.290 \\
\hline
\end{tabular}

Table 2: Coefficients of determination for distance-decay functions for intermunicipal commuting in Slovenia in 2010-2011, $R_{\mathfrak{C}}^{2}$ (Note: the bold number denotes the row maximum, the italic one denotes the column maximum, and the shaded cell denotes the maximum for the whole dataset).

Comparing the corresponding coefficients $R_{\mathfrak{M}}^{2}$ and $R_{\mathscr{C}}^{2}$ in relation to the destination, it is obvious that all functions (7-13) fit best for relative migration flows to urban centres of national significance (urban centres 2-1 or $k=2$ ). And for commuting, they fit best, in general, for relative commuting flows to urban centres at level $1 \quad(k=1)$. However, the coefficients for models of relative migration flows vary less $\left(0.14 \leq R_{\mathfrak{M}}^{2} \leq 0.66\right)$ than the coefficients for commuting functions $\left(0.11 \leq R_{\mathbb{E}}^{2} \leq 0.73\right)$. The coefficients are low for the whole set of interactions $\left(R_{M_{i j}^{0 \%}}^{2} \approx 0.16\right.$ and $\left.R_{C_{i j}^{0 \%}}^{2} \approx 0.15\right)$, but they increase significantly when distance-decay functions are modelled for urban centres at different levels of 
consideration $\left(0.32 \leq R_{M_{C K, i}^{0}}^{20} \leq 0.66\right.$ for migration and $0.33 \leq R_{C_{C K, i}^{20}}^{2} \leq 0.73$ for commuting).

These results indicate that in modelling of distance-decay functions of relative interactions between municipalities, it is logical to use the normalized power-exponential distance-decay function (13), which is defined only by two parameters, $a$ and $b$, and the shortest road distance. Table 3 and Table 4 show the estimated parameters of function (13) for migration and for commuting flows, respectively.

\begin{tabular}{|l|c|c|c|c|}
\hline & $S E E_{\mathfrak{M}}$ & $R_{\mathfrak{M}}^{2}$ & $a$ & $b$ \\
\hline All interactions & 0.004 & 0.173 & 2.771 & 0.216 \\
\hline To centres at level 1 & 0.013 & 0.436 & 1.665 & 0.210 \\
\hline To centres 2-1 & 0.004 & 0.655 & 1.677 & 0.315 \\
\hline To centres 3-2-1 & 0.004 & 0.367 & 1.943 & 0.293 \\
\hline To centres 4-3-2-1 & 0.002 & 0.553 & 2.230 & 0.266 \\
\hline To other municipalities & 0.001 & 0.375 & 3.203 & 0.210 \\
\hline
\end{tabular}

Table 3: Parameters of normalized power-exponential distance decay-function (13), $f(d)=e^{-a d^{b}}$, for inter-municipal migration in Slovenia and for the shortest road distance in 2010-2011.

\begin{tabular}{|l|c|c|c|c|}
\hline & $S E E_{\mathfrak{c}}$ & $R_{\mathfrak{c}}^{2}$ & $\boldsymbol{a}$ & $\boldsymbol{b}$ \\
\hline All interactions & 0.032 & 0.163 & 0.927 & 0.417 \\
\hline To centres at level 1 & 0.074 & 0.728 & 0.038 & 0.966 \\
\hline To centres 2-1 & 0.042 & 0.629 & 0.142 & 0.844 \\
\hline To centres 3-2-1 & 0.026 & 0.454 & 0.333 & 0.684 \\
\hline To centres 4-3-2-1 & 0.018 & 0.576 & 0.509 & 0.586 \\
\hline To other municipalities & 0.009 & 0.302 & 1.515 & 0.358 \\
\hline
\end{tabular}

Table 4: Parameters of normalized power-exponential distance decay-function (13), $f(d)=e^{-a d^{b}}$, for inter-municipal commuting in Slovenia and for the shortest road distance in 2010-2011.

Graphical presentations of normalized power-exponential distance decayfunction (13), whose parameters are presented in Tables 3 and 4, are given in Figure 2 for relative migration flows, and in Figure 3 for relative commuting flows. Note that for better readability and differentiation between functions, the $x$ axes for relative flows are limited to $30 \mathrm{~km}$, and the $y$ axis for relative migration flows is limited to $25 \%$.

It is evident that the impact of the distance is much higher for intensity of migration than for intensity of commuting flows. It means that the relative intensity of commuting decreases much more slowly with the distance from the centre than the relative migration flows. This is especially the case for interactions to urban centres at the two highest levels (to national urban centres of international significance and to urban centres of national significance). The 
reason is that these centres are the most important employment centres in the state (e.g., in 2011, 62.5\% of all working places in Slovenia were provided there).

It is also evident that much larger relative out-flows of commuters originate from distant origins than relative migration flows. In other words, Slovenia is such a small country that several important flows of commuters occur even at relatively long distances (covering even half the width of the territory; for example, approx. $140 \mathrm{~km}$ from Maribor to Ljubljana or approx. $110 \mathrm{~km}$ from Koper to Ljubljana). All these centres are connected by new highways.

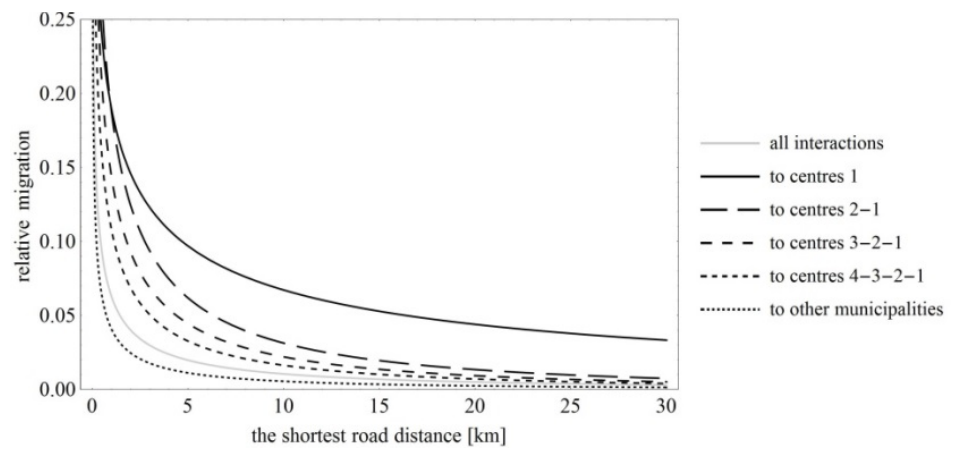

Figure 2: Normalized power-exponential distance decay-function (13), $f(d)=e^{-a d^{b}}$, for inter-municipal migration in Slovenia in 2010-2011.

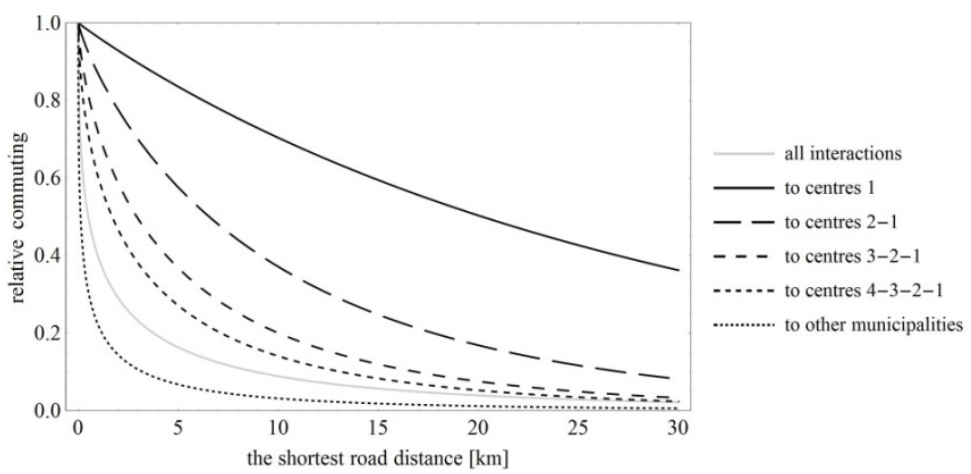

Figure 3: Normalized power-exponential distance decay-function $(13), f(d)=e^{-a d^{b}}$, for inter-municipal commuting in Slovenia in 2010-2011.

The comparison between the distance function for the whole set of interactions of migrants and the functions of migration flows to each group of centres suggests that the highest differences are between the distance function for centres 1 and the function for all interactions - the difference is the highest for small distances $(+0.77$ at $5 \mathrm{~km})$ and lower for longer distances (e.g., +0.030 at $30 \mathrm{~km}$ ). Likewise, the intensity of commuting flows to centres 1 differs most from the intensity of all commuting flows, but the difference is much higher 
than for migration flows - especially for longer distances (e.g., +0.671 at $5 \mathrm{~km}$ and +0.337 at $30 \mathrm{~km}$ ).

For both migration and commuting distance functions to urban centres lie higher than the distance function for the whole set of adequate data for distances of up to $35 \mathrm{~km}$. But, if the distance of commuting is more than $35 \mathrm{~km}$, the intensity of commuting flows to centres 4-3-2-1 is lower than for the whole set of interactions.

Comparing the intensity of migration flows to commuting flows, one cannot fail to observe that the intensity of commuting flows is much higher than that of migration flows: the highest difference between them is at approx. $5 \mathrm{~km}$ for the whole datasets, at approx. $20 \mathrm{~km}$ for the flows to centres 1, at approx. 15 $\mathrm{km}$ for the flows to centres 2-1, at approx. $10 \mathrm{~km}$ for the flows to centres 3-2-1 and to centres 4-3-2-1, and at approx. $5 \mathrm{~km}$ for the flows to other municipalities.

\section{Conclusions}

In this paper, we analysed the impact of the distance on the intensity of migration and commuting flows between municipalities in Slovenia. The analysis was performed for the whole sets of interactions for the period of two years (2010-2011) and for subsets of flows terminating in urban centres at different levels of consideration. Seven different functions were fitted to the datasets. Our results - that are accordant with [13] - show that the interactions are best described by the power-exponential model: this applies to both migration and commuting flows. Moreover, a simpler version of the function, the normalized power-exponential function, can be used in different applications without a significant loss of validity of the results.

The results also show that determination coefficients are much higher when distance functions are fitted to flows to urban centres at different levels of consideration: for commuting, the model of relative interactions to national urban centres of international importance (centres 1) is defined by the highest value of the determination coefficient, but for migration, the highest value of the determination coefficient was calculated when the power-exponential function was fitted to relative migration flows to urban centres of national significance without the centres at the higher level (centres 2-1). As already noted by Halas et al. [13], the relative variability of the values of the coefficient of determination reflects the heterogeneity of the geographical space. So, the high values of the coefficients of determination indicate that the power-exponential function expresses the interactions to the analysed destinations relatively well. This is the case for commuting to national urban centres of international importance (centres 1), for migration and commuting to urban centres of 
national importance without national urban centres of international importance (centres 2-1), and for migration and commuting to urban centres of intermunicipal significance without the centres at the higher levels (centres 4-3-2-1). The lower values of the coefficient of determination indicate flows to the centres with potentially deformed hinterlands [13]. This is especially the case for migration to urban centres of regional significance without the centres at the higher level (centres 3-2-1) - here the distance does not play such an important role in relation to the above-mentioned cases.

The influence of the distance on the relative out-flows is much higher for migration than for commuting flows. For example, for distances between 5 and $30 \mathrm{~km}$, it is approx. 8 times higher for the whole set of interactions as well as for flows to urban centres of regional importance without the centres at the higher levels (centres 3-2-1), and it is approx. 11 times higher for flows to urban centres at the two highest levels (centres 1 and centres 2-1). The results also show that national urban centres of international significance (centres 1) are relatively highly attractive to commuters. Here, the attractiveness forms the power-exponential distance-decay function in a shape similar to the linear function. These results show that there are still many people that do not want to migrate to regional centres of Slovenia and they decide to commute - this is especially the case for interactions to urban centres at the highest level of consideration (i.e., Ljubljana, Maribor and conurbation Koper-Izola-Piran).

Here, we should raise some methodological doubts. Fotheringham and O'Kelly wrote "... the exponential function is more appropriate for analysing short distance interactions such as those that take place within an urban area. The power function, conversely, is generally held to be more appropriate for analysing longer distance interactions such as migration flows" [11:12-13]. But, de Vries et al. [4], who fitted exponential and power distance-decay functions to commuting data in Denmark, showed that neither an exponential nor a power distance-decay function fitted the data well (a power function was a too simple representation of reality: it fitted better than the exponential function, but performed poorly for very small and very large distances). For this reason, they suggested the research on the S-shaped curve(s).

Bole and Gabrovec [1] warned about the problems arising from the methodology of data collection in the statistical database that was used in our analysis: the misstatement of the place of residence or the place of work and the lack of data on the actual travel of employees. The results of this study, therefore, need to be critically addressed.

In the future, further investigation into the dynamics of the parameters of distance-decay functions for interactions to urban centres in a specific time series (e.g., before and after the recession in the EU) should be obtained. Moreover, it would make sense to explore the ways and means of modelling the 
anisotropic influence of the distance on interactions, and the possibility of modelling the 'radius of influence'; as it was modelled in [13] for a specific regional centre. Nevertheless, the distance-decay model for commuting to specific regional centres of Slovenia has been already suggested by Drobne and Lakner [5].

\section{References}

[1] Bole, D. and Gabrovec, M. (2012). Daily commuters in Slovenia. Geografski Vestnik (Geographical Gazette), 84, 171-185.

[2] Cesario, F. J. (1973). A generalized trip distribution model. Journal of Regional Science, 13, 233-247.

[3] Cesario, F. J. (1974). More on the generalized trip distribution model. Journal of Regional Science, 14, 389-397.

[4] de Vries, J. J., Nijkamp, P. and Rietveld, P. (2009). Exponential or power distancedecay for commuting? An alternative specification. Environment and Planning A, 41, 461-480.

[5] Drobne, S. and Lakner, M. (2014). Model vpliva razdalje na delovno mobilnost v regionalna središča Slovenije (Distance-decay model for commuting to regional centres of Slovenia, in Slovene only). In Ciglič, R., Perko, D. and Zorn, M. (Eds.). Digitalni prostor. GIS v Sloveniji 12 (135-153). Ljubljana: Znanstvenoraziskovalni center Slovenske akademije znanosti in umetnosti.

[6] Drobne, S., Rajar, T. and Lisec, A. (2013). Dinamika selitev in delovne mobilnosti v urbana središča Slovenije, 2000-2011 (Dynamics of migration and commuting to the urban centres of Slovenia, 2000-2011), Geodetski vestnik (Geodetic Gazette), 57, 313-332.

[7] Evers, G. H. M. and Van der Veen, A. (1985). A simultaneous non-linear model for labour migration and commuting. Regional Studies, 19, 217-229.

[8] Fotheringham, A. S. (1980). Spatial structure, spatial interaction, and distancedecay parameters. Open Access Dissertations and Theses, Paper 629.

[9] Fotheringham, A. S. (1981). Spatial structure and distance-decay parameters. Annals of the Association of American Geographers, 71, 425-436.

[10] Fotheringham, A. S. (1984). Spatial flows and spatial patterns. Environment and Planning A, 16, 529-543.

[11] Fotheringham, A. S. and O'Kelly, M. E. (1988). Spatial Interaction Models: Formulations and Applications. Dordrecht: Springer.

[12] Goux, J. M. (1962). Structure de l'espace et migration. In Sutter, J. (Ed.). Human displacements: Measurement methodological aspects (167-172). Monaco: Entretiens de Monaco en sciences humaines.

[13] Halás, M., Klapka, P. and Kladivo, P. (2014). Distance-decay functions for daily travel-to-work flows. Journal of Transport Geography, 35, 107-119.

[14] Haynes, K. E. and Fotheringham, S. (1984). Gravity and Spatial Interaction Models. Beverly Hills: Sage Publications, Inc. 
[15] Lundholm, E. (2010). Interregional migration propensity and labour market size in Sweden, 1970-2001. Regional Studies, 44, 455-464.

[16] Ministry of Environment (2004). Spatial Development Strategy of Slovenia. http://www.mop.gov.si/fileadmin/mop.gov.si/pageuploads/publikacije/drugo/e n/sprs_eng.pdf [Accessed on 15 June 2014].

[17] Johnston, R. J. (1973). On frictions of distance and regression coefficients. Area 5, 187-191.

[18] Olsson, G. (1965). Distance and human interaction. A migration study. Geografiska Annaler. Series B, Human Geography. 47, 3-43.

[19] Ravenstein, E. (1885). The laws of migration, Journal of the Statistical Society, 48, $167-235$.

[20] Sheppard, E. S. (1978). Theoretical underpinnings of the gravity hypothesis. Geogr. Anal. 10, 386-402.

[21] Slovenian Roads Agency (2013). Network of State Roads, Slovenia, Years 2010 and 2011. Ljubljana.

[22] Statistical Office of Slovenia (2013). Migration and commuting flows between municipalities in Slovenia, Yearly.

http://pxweb.stat.si/pxweb/dialog/statfile1.asp [Accessed on 1 December 2013].

[23] Stewart, J. Q. (1941). An inverse distance variation for certain social influences. Science, 93, 89-90.

[24] Stewart, J. Q. (1948). Demographic gravitation: Evidence and applications. Sociometry, 11, 31-58.

[25] Taylor, P. J. (1971). Distance transformation and distance decay function. Geographical Analysis. 3, 221-238.

[26] Taylor, P. J. (1975). Distance decay in spatial interactions. Concepts and Techniques in Modern Geography. London: GeoBooks.

[27] Ministry of Environment, Spatial Planning and Energy (2004). Spatial Development Strategy of Slovenia.

[28] Tobler, W. (1970). A computer movie simulating urban growth in the detroit region. Economic Geography 46, 234-240.

[29] Wilson, A. G. (1974). Urban and regional models in geography and planning. Chichester and New York: John Wiley.

[30] Yapa, L., Polese, M. and Wolpert, J. (1971). Interdependencies of commuting, migration, and job site relocation. Economic Geography 47, 59-72. 